\title{
Çukurova Bölgesinde Nohut (Cicer arietinum L.) Genotiplerinin Kışlık Ekim Zamanında Verim ve Morfolojik Özelliklerinin Değerlendirilmesi
}

\author{
*Dürdane MART \\ Derya YÜCEL \\ Meltem TÜRKERI
}

Doğu Akdeniz Tarımsal Araştırma Enstitüsü, Adana

*Sorumlu yazar e-posta (Corresponding author e-mail): durdanemart@yahoo.com

\section{Öz}

$\mathrm{Bu}$ araştırma, Çukurova iklim koşullarında nohut (Cicer arietinum L.) çeşit ıslahı amacıyla nohut hat ve çeşitlerinin 2013-2014 üretim döneminde ekilerek verim ve verimle ilgili bazı özellikler incelenmiştir. Denemeler, Doğu Akdeniz Tarımsal Araştırma Enstitüsü Araştırma Alanında Doğankent lokasyonunda yürütülmüştür. Araştırmada kışlık olarak 20 genotip ve çeşit ekilerek değerlendirilmiştir. Yapılan çalışmada nohut genotiplerinden kışlık ekime yönelik seleksiyon ve değerlendirmeleri yapılmıştır. Araştırmanın yürütüldüğü yılda kışlık ekimlerden elde edilen en yüksek tane verim değeri 388.8 kg/da olarak FLIP 07-184 C hattından en düşük tane verim değeri 112.9 kg/da olarak FLIP 06-158C hattından elde edilmiştir. 100 tane ağılığı bakımından da 44.3-31.4 g ile en yüksek ve düşük değerler arasında değişim göstermiştir. Bunlara ilave olarak çiçeklenme ve bitki boyu değerlendirmeleri de seleksiyon kriteri olarak değerlendirilmiştir. Araştırmanın yürütüldüğü yılda hat ve çeşitler üzerinde iklime bağlı yağışların gecikmesi ve çiçeklenme döneminin uygun koşullarda olması nedeniyle antraknozun olumsuz etkisi tespit edilmemiştir.

Anahtar Kelimeler: Kışlık nohut, verim, çeşit ıslahı

\section{Evaluation of Chickpea (Cicer arietinum L.) Lines Interms of Yield and Morphologic Properties Under Winter Conditions of Çukurova Region}

\begin{abstract}
This research was conducted with aim to variety breeding determine the suitability Chickpea lines under winter conditions of Cukurova region in 2013-2014 seasons. The researches were carried out in Eastern Mediterranean Research Institute with 20 genotype and cultivar. Winter sowing selection were done in the research. The highest yield were obtained from FLIP 07-184 C line with $388.8 \mathrm{~kg} / \mathrm{da}$, buth the lowest value was obtained from FLIP 06-158C line with $112.9 \mathrm{~kg} / \mathrm{da}$. 100 seed weight were ranged from 44.3 to $31.4 \mathrm{~g}$. Besides, flowering time and plath height were used as selection criteries. During the research year, negative effect of ascochyta were not determined because of the weather condition on investigated chickpea lines and cultivars.
\end{abstract}

Keywords: Winter chickpea, yield, variety breeding

\section{Giriş}

Y emeklik tane baklagillerden nohut ülkemizde insan beslenmesinde kullanılan ve önemli bitkisel protein kaynağı olan bitkilerdendir; Protein zenginlikleri bakımından insan beslenmesinde (Bitkisel proteinlerin $\% 22$, karbonhidratların $\% 7$ yemeklik tane baklagillerden sağlanmaktadır) önemli bir konumda olup temel besin maddelerindendir. Nohut besin değerleri bakımından zengin oldukları gibi yetiştirildikleri toprağa da olumlu katkıları bulunmaktadır. Nohut genellikle ülkemizde kıraç ve sulama imkanı olmayan bölgelerde yetiştirilmektedir. Türkiye'de ise 423.557 ha ekim alanı, 530.634 ton üretimi, birim alandan alınan tane verimi ise 119 kg/da'dır (Tüík 2014). Türkiye'de baklagil sanayisi de önemli; özellikle baklagillerde işleme, paketleme sanayi ve çeşitli leblebi yapımı ve gelişen bir sanayi kolu nohutun önemini arttırmaktadır.

Yemeklik tane baklagillerden nohutta en önemli problem antraknoza toleranslılık ve makinalı tarıma uygunluğu olmaktadır. Yürütülen ıslah çalışmalarında hastalıklara özellikle 
Çizelge 1. Adana ilinin 2012-2013 ve 2013-2014 yetiştirme yıllarında yağış, ortalama sıcaklık ve toplam oransal nem değerleri

Table 1. Total precipitations, average temperatures and moisture contents of Adana province in 2012-2016 and 2013-2014 growing seasons

\begin{tabular}{lccccccccc}
\hline \multirow{3}{*}{ Aylar } & \multicolumn{3}{c}{ Yağış $(\mathrm{mm})$} & \multicolumn{3}{c}{ Ortalama Sıcaklık ${ }^{\circ} \mathrm{C}$} & \multicolumn{3}{c}{ Nisbi nem (\%) } \\
& Uzun & $2012-$ & $2013-$ & Uzun & $2012-$ & $2013-$ & Uzun & $2012-$ & $2013-$ \\
& Yllar & 2013 & 2014 & Yıllar & 2013 & 2014 & Yıllar & 2013 & 2014 \\
\hline Kasım & 67.2 & 187 & 1.0 & 15.3 & 17.4 & 17.7 & 63 & 52.3 & 57.5 \\
Aralık & 118.1 & 154.4 & 12.2 & 11.1 & 11.4 & 10.4 & 66 & 73.7 & 42.7 \\
Ocak & 111.7 & 25.9 & 28.19 & 9.7 & 9.5 & 11.48 & 66 & 66.8 & 69.58 \\
Şubat & 92.8 & 49.0 & 18.54 & 10.4 & 12.1 & 10.84 & 66 & 73.9 & 56.90 \\
Mart & 67.9 & 70.1 & 56.09 & 13.3 & 13.9 & 15.06 & 66 & 61.1 & 65.55 \\
Nisan & 51.4 & 43.2 & 18.56 & 17.5 & 18.1 & 17.68 & 69 & 72.0 & 66.94 \\
Mayıs & 46.7 & 57.4 & 22.36 & 21.7 & 22.7 & 21.26 & 67 & 72.3 & 70.39 \\
Haziran & 22.4 & 0.3 & 50.04 & 25.6 & 25.3 & 24.03 & 66 & 65.7 & 68.19 \\
Temmuz & 5.4 & 0.0 & 0.25 & 27.7 & 28.2 & 28.23 & 68 & 65.2 & 72.58 \\
\hline
\end{tabular}

antraknoz hastalığına toleranslı makinalı hasat ve harmana uygun çeşitlerin geliştirilerek çiftçinin hizmetine sunulmasıdır. Üretim amacının yüksek tane ürünü olması nedeniyle, nohutta da yetiştirileceği bölgeye uygun çeşitlerin geliştirilmesi, üretimin ve kalitenin arttırılmasında önemli bir faktördür.

Bu araştırma, Çukurova bölgesi için kışlık olarak yetiştirilebilecek, yüksek verimli, orta ve iri taneli, kaliteli, hastalık ve zararlılara dayanıklı/toleranslı yeni nohut çeşitlerinin geliştirilebilmesi amacıyla ıslah çalışmaları yürütülmektedir. Bu çalışma da ıslah çalışmalarımızdan bir bölümüdür.

\section{Materyal ve Yöntem}

Araştırmada, ülkesel projeden ve ICARDA materyallerinden seçilen nohut hatlarından oluşan materyaller ile kışlık ekim yapılarak değerlendirilmiştir. 20 hat ve çeşitten oluşan nohut ıslah materyalimiz deneme alanına ekilerek bölge iklim koşullarında kışlık ekime yönelik seleksiyon ve gözlemler yapılmıştır. Bu çalışma ile ileri çıkmış hatların arazi koşullarında reaksiyonları ve kalite değerleri araştırılarak yüksek verimli ve kaliteli hatlar tespit edilerek çeşit tesciline yönelik ıslah çalışmaları yapılmaktadır.

Bu araştırma; Doğu Akdeniz Tarımsal Araştırma Enstitüsü (Adana), araştırma-deneme alanında taban arazi koşullarında, 2012-2013 ve 2013-2014 yetiştirme sezonlarında yürütülmüştür. Ekimler, sıra arası $45 \mathrm{~cm}$, sıra üzeri $8 \mathrm{~cm}$ olacak şekilde, $5 \mathrm{~m}$ uzunluğundaki 4 sıraya (9 $\mathrm{m}^{2}$ 'lik parsellere) yapılmıştır. Ekim öncesi dekara 2-3 kg N, 5-6 kg $\mathrm{P}_{2} \mathrm{O}_{5}$ gelecek şekilde gübreleme yapılmıştır. Her parselden bazı önemli morfolojik gözlemler yapılmıştır.
Ayrıca çeşit ve hatlarda antraknoz yanıklığı hastalığına doğal koşullarda toleransları belirlemek için gerekli okumalar yapılmıştır.

\section{Deneme Alanının İklim Özellikleri}

Çizelge 1 incelendiğinde, Adana iklim yapısı, nohutun üretim dönemindeki aylık yağış, sıcaklık ve nisbi nem oranları görülmektedir. Özellikle de yağışların yetişme mevsimlerine dengeli dağılmadığı, 2012-2013 yılında Kasım, Aralık uzun yıllara göre yoğun yağış baskısı ve dengesiz yağış dağılımı bitkilerin gelişimi üzerinde olumsuz etkide bulunmuştur.20132014 yılında da Kasım, Aralık, Ocak ve Şubat aylarında ekim zamanında, gelişme dönemlerinde uzun yıllar ortalamasına göre düşük yağış aldığı görülmektedir. Her iki yılda da dengesiz yağış dağılımı bitkilerin gelişimi üzerinde olumsuz etkide bulunmuştur.

\section{Bulgular ve Tartışma}

2012-2013 yetiştirme sezonunda Doğu Akdeniz Tarımsal Araştırma Enstitüsü Doğankent deneme alanında kışlık olarak yetiştirilen çeşitlerin verim değerleri Çizelge 2'de verilmiştir. Yağış miktarındaki düzensiz dağlımı nedeniyle verimlerde ve 100 tane ağırlıklarında olumsuz etkileri gözlenmiştir.

Çizelge 2'de tane verimi bakımından en yüksek verim değerleri İnci çeşidinden 353.93 kg/da, Seçkin çeşidinden 278.07 kg/da ve FLIP 06-59C hattından $275.41 \mathrm{~kg} / \mathrm{da}$ saptanmıştır. En düşük değer ise FLIP 85-1C hattından 4.67 kg/da elde edilmiştir. 2014 yılında yağış miktarının uzun yıllara göre dağılımın düzensiz olması verimde kayıplara neden olmuştur. Özellikle de mayıs ayında çiçeklenme döneminde düşen yağışlar antraknoz hastalığını arttırmıştır. 
Çizelge 2. 2012-13 yetiştirme sezonunda, nohut çeşit ve hatlarının tane verimi (kg/da), 100 tane ağırlığı (g), çiçeklenme gün sayısı (gün), bitki boyu $(\mathrm{cm})$ ve hastalık değerleri

Table 2. Grain yields (kg/da), 100 grain weights (g), days to flowering (gün), plant heights (cm) and disease ratings of chickpea lines and varieties in 2012-2013

\begin{tabular}{|c|c|c|c|c|c|c|}
\hline $\begin{array}{c}\text { Sira } \\
\text { no }\end{array}$ & Çeşitler & $\begin{array}{l}\text { Verim } \\
\text { (kg/da) }\end{array}$ & $\begin{array}{l}100 \text { tane } \\
\text { ağ. }(g)\end{array}$ & $\begin{array}{c}\text { Çiçek gün sayısı } \\
\text { (gün) }\end{array}$ & $\begin{array}{l}\text { Bitki boyu } \\
\quad(\mathrm{cm})\end{array}$ & Hastalık \\
\hline 1 & îNCi & $353.93 \mathrm{~A}$ & 36.63 & 116.33 & 79.97 & 1 \\
\hline 2 & SEÇKIN & $278.07 \mathrm{AB}$ & 40.67 & 112.00 & 81.07 & 1 \\
\hline 3 & FLIP 06-59C & $275.41 \mathrm{AB}$ & 40.83 & 111.00 & 75.53 & 1 \\
\hline 4 & FLIP 06 111C & $257.04 \mathrm{~A}-\mathrm{C}$ & 38.20 & 114.33 & 81.60 & 1 \\
\hline 5 & FLIP $06133 C$ & 246.07 A-D & 42.87 & 116.67 & 84.43 & 1 \\
\hline 6 & HASANBEY & 227.78 A-E & 41.07 & 114.33 & 77.17 & 3 \\
\hline 7 & FLIP $93-93 C$ & 213.04 A-E & 34.63 & 114.67 & 80.53 & 3 \\
\hline 8 & FLIP97-677C & $178.44 \mathrm{~B}-\mathrm{F}$ & 40.40 & 115.00 & 69.40 & 3 \\
\hline 9 & EN1788 & $161.48 \mathrm{~B}-\mathrm{G}$ & 40.60 & 112.33 & 59.53 & 4 \\
\hline 10 & FLIP 97-503C & $151.93 \mathrm{~B}-\mathrm{G}$ & 39.33 & 115.67 & 74.43 & 3 \\
\hline 11 & EN 1830 & 142.22 B-G & 39.93 & 115.67 & 77.73 & 4 \\
\hline 12 & EN 1831 & $133.19 \mathrm{~B}-\mathrm{G}$ & 39.53 & 114.67 & 87.73 & 4 \\
\hline 13 & EN 1822 & 131.11 B-G & 38.87 & 115.67 & 74.40 & 5 \\
\hline 14 & EN 1800 & $121.78 \mathrm{~B}-\mathrm{G}$ & 41.50 & 118.67 & 78.30 & 5 \\
\hline 15 & FLIP 98-121C & $92.00 \mathrm{C}-\mathrm{G}$ & 34.87 & 110.33 & 65.50 & 6 \\
\hline 16 & EN 1823 & $86.59 \mathrm{D}-\mathrm{G}$ & 36.63 & 117.33 & 79.97 & 7 \\
\hline 17 & EN 1799 & $74.15 \mathrm{E}-\mathrm{G}$ & 37.10 & 116.67 & 80.50 & 6 \\
\hline 18 & FLIP 87-8C & 28.37 F-G & 31.77 & 116.00 & 66.60 & 7 \\
\hline 19 & ILC 464 & $5.33 \mathrm{G}$ & 38.67 & 118.00 & 67.77 & 7 \\
\hline \multirow[t]{2}{*}{20} & FLIP $851 \mathrm{C}$ & $4.67 \mathrm{G}$ & 38.33 & 120.33 & 58.10 & 7 \\
\hline & AÖF & ** & ÖD & ÖD & ÖD & \\
\hline
\end{tabular}

100 tane ağırlığı bakımından en yüksek değer FLIP $06133 \mathrm{C}$ hattından $42.87 \mathrm{~g}$, en düşük değer de FLIP $87-8 \mathrm{C}$ hattından $31.77 \mathrm{~g}$ olarak tespit edilmiştir. Diğer hatlarda da değişimler bu iki değer arasında değişim göstermiş̧tir. Yüz tane ağırlığı üzerinde yağış miktarının düşük ve dağılımın düzensiz olması olumsuz etkilenmeler olmuştur. Özellikle de daha hassas ve erkenci olan nohut çeşitlerinde görülen hastalık da tane irilikleri üzerinde olumsuz etkide bulunmuştur. Hastalık nedeniyle bitkide kırılmalar ve gelişme geriliği nedeniyle taneler zayıf kalmalar tespit edilmiştir.

Çiçeklenme gün sayısı bakımından en yüksek değer FLIP 85 1C hattından 120.3gün ile en geççi çeşit olmuştur. Çiçeklenme gün sayısı bakımından en düşük değer FLIP 98121C hattından 110.33 gün ile en erkenci hat olmuşlardır. Yetiştirme yılında düşen yağış miktarının dağııımının düzensiz olması, özellikle çiçeklenme döneminde düşen Mayıs yağışları genotiplerde antraknoz yanıklığı hastalığı etkinliğini arttırmış ve çiçeklenmeyi de olumsuz etkilemiştir. Çiçeklenme gün sayısı çeşit ve hatların erkencilik ve geçcilik durumları bakımından önemli bir ıslah kriteri olmaktadır.

Bitki boyu bakımından en yüksek değer FLIP 06 133C hattından $84.43 \mathrm{~cm}$ ile en uzun boylu hat; Bitki boyu bakımından en düşük değer FLIP
$851 \mathrm{C}$ hattından $58.10 \mathrm{~cm}$ ile en kısa boylu hatlar olmuşlardır. Yetiştirme sezonunun iklim verilerinin ve özellikle yağış dağıımının ekstrem bir yıl olmasına rağmen; Alınan bu değerler çalışmada kullanılan genotiplerin kışlık ekimde makinalı hasata uygunluğunu göstermiştir. Makinalı hasata uygunluk için bitki boyu önemli değerlendirme kriteri olmaktadır.

Araştırmada kullanılan genotiplere ait antraknoz hastalığı değerleri de (1-9 skalasında okuma yapılmıştır) Çizelge 2'de görülmektedir. Kışlık ekimlerde çeşitlerin Ascochyta yanıklığına dayanıklı veya toleranslı olması gerekmektedir. Nohut bitkisinde tane iriliği ile Ascochyta yanıklığı arasında ters ilişki bulunmaktadır; Tane iriliği arttıkça hastalığa hassaslık artmaktadır. Bu nedenle Antraknoza toleranslı ve iri taneli nohut çeşitlerinin geliştirilmesi için hastalığın ve materyallerin çok iyi bilinmesi gerekmektedir. Bu nedenle de hastalık okumaları her çeşit ve hatta okumalar 2-3 defa okunarak materyal değerlendirilir.

2013-2014 yetiştirme sezonunda Doğu Akdeniz Tarımsal Araştırma Enstitüsü Doğankent deneme alanında kışlık olarak yetiştirilen çeşitlerin verim değerleri Çizelge 3'de verilmiştir. Yağış miktarındaki düşüklük ve düzensiz dağlımı nedeniyle verimlerde ve 100 tane ağırlıklarında olumsuz etkileri gözlenmiştir. 
Çizelge 3. 2013-14 yetiştirme sezonunda, nohut çeşit ve hatlarının tane verimi (kg/da), 100 tane ağırlığı (g), çiçeklenme gün sayısı (gün), bitki boyu $(\mathrm{cm})$ ve hastalık değerleri

Table 3. Grain yields (kg/da), 100 grain weights (g), days to flowering (gün) and plant heights (cm) of chickpea lines and varieties in 2013-2014

\begin{tabular}{clccccc}
\hline $\begin{array}{c}\text { Sıra } \\
\text { no }\end{array}$ & \multicolumn{1}{c}{ Çeşitler } & $\begin{array}{c}\text { Verim } \\
(\mathrm{kg} / \mathrm{da})\end{array}$ & $\begin{array}{c}100 \text { tane ağ. } \\
(\mathrm{g})\end{array}$ & $\begin{array}{c}\text { Çiçek gün } \\
\text { sayısı }(\mathrm{gün})\end{array}$ & $\begin{array}{c}\text { Bitki boyu } \\
(\mathrm{cm})\end{array}$ & Hastalık \\
\hline 1 & FLIP 05-150 C & 241.1 & $46.9 \mathrm{ab}$ & $61.3 \mathrm{be}$ & 81.1 & 1 \\
2 & FLIP 05-170 C & 251.6 & $45.4 \mathrm{ab}$ & $59.6 \mathrm{de}$ & 88.3 & 1 \\
3 & FLIP 01-24 C & 295.0 & $50.1 \mathrm{a}$ & $60.3 \mathrm{ce}$ & 70.0 & 1 \\
4 & EN-1683 & 270.6 & $46.2 \mathrm{ab}$ & $60.3 \mathrm{ce}$ & 81.1 & 2 \\
5 & EN-1685 & 197.0 & $44.7 \mathrm{ac}$ & $60.6 \mathrm{ce}$ & 93.8 & 3 \\
6 & EN-1750 & 313.4 & $44.7 \mathrm{ac}$ & $58.6 \mathrm{de}$ & 82.2 & 1 \\
7 & EN-1751 & 301.3 & $49.3 \mathrm{a}$ & $58.6 \mathrm{de}$ & 60.0 & 1 \\
8 & EN-1685-1 & 230.1 & $47.8 \mathrm{ab}$ & $62.0 \mathrm{be}$ & 76.6 & 1 \\
9 & ÜNHB-2010-52 & 331.6 & $50.5 \mathrm{a}$ & $64.6 \mathrm{ac}$ & 96.1 & 1 \\
10 & ÜNHB-2010-95 & 201.1 & $44.1 \mathrm{ac}$ & $60.6 \mathrm{ce}$ & 86.1 & 1 \\
11 & ÜNHB-2010-96 & 260.0 & $45.3 \mathrm{ab}$ & $59.3 \mathrm{de}$ & 75.5 & 2 \\
12 & ÜNHB-201-97 & 232.9 & $43.7 \mathrm{ac}$ & $62.3 \mathrm{be}$ & 88.3 & 1 \\
13 & EN-1788 & 278.8 & $43.3 \mathrm{ac}$ & $58.0 \mathrm{e}$ & 67.7 & 2 \\
14 & EN-1800 & 276.0 & $48.1 \mathrm{ab}$ & $62.6 \mathrm{bd}$ & 106.6 & 2 \\
15 & EN-1822 & 347.8 & $47.6 \mathrm{ab}$ & $60.0 \mathrm{de}$ & 74.9 & 2 \\
16 & EN-1823 & 234.8 & $43.6 \mathrm{ac}$ & $62.3 \mathrm{be}$ & 91.6 & 2 \\
17 & EN-1830 & 266.4 & $46.4 \mathrm{ab}$ & $61.3 \mathrm{be}$ & 75.5 & 1 \\
18 & HASAN BEY & 362.6 & $43.2 \mathrm{ac}$ & $59.3 \mathrm{de}$ & 69.9 & 1 \\
19 & SECKIN & 259.7 & $38.9 \mathrm{bc}$ & $67.3 \mathrm{a}$ & 71.6 & 1 \\
20 & INCi & 360.8 & $35.1 \mathrm{c}$ & $65.6 \mathrm{ab}$ & 68.8 & 1 \\
\hline
\end{tabular}

Çizelge 3'de tane verimi bakımından en yüksek verim değerleri Hasanbey çeşidinden $362.6 \mathrm{~kg} / \mathrm{da}$, İnci çeşidinden $360.8 \mathrm{~kg} / \mathrm{da}$, EN 1820 hattından $347.8 \mathrm{~kg} / \mathrm{da}$ saptanmıştır; En düşük değer ise EN 1685 hattından $197 \mathrm{~kg} / \mathrm{da}$ değerleri elde edilmiştir. 2014 yılında yağış miktarının uzun yıllara göre düşük ve dağılımın düzensiz olması verimde kayıplara neden olmuştur. Özellikle de Nisan ve Mayıs ayında çiçeklenme döneminde düşen yağış miktarının düşüklüğü antraknoz hastalığının yoğun olmamasına neden olmuştur.

100 tane ağırlığı bakımından en yüksek değerler ÜNHB-2010-52 50.5 g, FLIP 01-24 C $50.1 \mathrm{~g}$ ve $\mathrm{EN}-175149.3 \mathrm{~g}$ hatlarından, en düşük değer de İnci çeşitinden $35.1 \mathrm{~g}$ olarak tespit edilmiştir. Diğer hatlarda da değişimler bu iki değer arasında değişim göstermiştir. Yüz tane ağırlığı üzerinde yağış miktarının düşük ve dağılımın düzensiz olması olumsuz etkilenmeler olmuştur. Bitkilerde gelişme geriliği ve tanelerde zayıf kalmalar tespit edilmiştir.

Çiçeklenme gün sayısı bakımından en yüksek değer Seçkin çeşitinden 67.3 gün ile en geççi çeşit olmuştur. Çiçeklenme gün sayısı bakımından en düşük değer EN-1788 hattından 58 gün ile en erkenci hat olmuşlardır. Yetiştirme yılında düşen yağış miktarının özellikle ekim zamanında düşük olması, genotiplerde çıkışı çok geciktirmiştir.

Bitki boyu bakımından en yüksek değer EN1800 hattından $106.6 \mathrm{~cm}$ ile en uzun boylu hat; Bitki boyu bakımından en düşük değer EN-1751 hattından $60 \mathrm{~cm}$ ile en kısa boylu hatlar olmuşlardır. Yetiştirme sezonunun iklim verilerinin ve özellikle yağış dağııııının ekstrem bir yıl olması rağmen; Alınan bu değerler çalışmada kullanılan genotiplerin kışlık ekimde makinalı hasata uygunluğunu göstermiştir.

Araştırmada kullanılan genotiplere ait Antraknoz hastalığı değerleri de (1-9 skalasında okuma yapılmıştır) Çizelge 3'de görülmektedir. 2013-2014 yılındaki yağış miktarı ve dağılımından dolayı antraknoz hastalığı çok etkili olmamıştır. Özellikle kışlık ekimlerde çeşitlerin Ascochyta yanıklığına dayanıklı veya toleranslı olması gerekmektedir. Bu nedenle de hastalık okumaları hastalığın yoğunluğuna göre her çeşit ve hatta okumalar 2-3 defa da okunarak materyal değerlendirilir.

\section{Sonuç}

Yapılan gözlem ölçümler neticesinde, yüksek verimli hat ve çeşitlerin seçiminde, araştırmanın yürütüldüğü lokasyonda incelenen özellikler içerisinde kışlık ekimde nohut genotiplerinden, 
2012-13 yılı için tane verimi bakımından en yüksek verimler İnci çeşidinden $353.93 \mathrm{~kg} / \mathrm{da}$, Seçkin çeşidinden 278.07 kg/da ve FLIP 06-59C hattından $275.41 \mathrm{~kg} / \mathrm{da}$; 2013-14 yılı için tane verimi bakımından en yüksek verimler Hasanbey çeşidinden $362.6 \mathrm{~kg} / \mathrm{da}$, İnci çeşidinden 360.8 $\mathrm{kg} / \mathrm{da}$, EN 1820 hattından $347.8 \mathrm{~kg} / \mathrm{da}$ çeşit ve hatlarından saptanmıştır. Dolaysıyla da bu hatlar dikkati çeken genotipler olmuşlardır. Yağış miktarının düşük ve dağılımın düzensiz olması verimde kayıplara neden olmuştur.

\section{Kaynaklar}

Anonim 2014. TÜIKK.

Açikgöz N., 1987. Nohut Tarımı. Ege Bölge Zirai Arş. Ens. Müd. Yayın No: 76, Menemen-İzmir, 25 s

Finlay K.W. and Wilkinson G.N., 1966. The analysis of adaptation in plant breeding programe. Aust. J. Agric. Res., 14: 742-754

Mart D. ve Anlarsal E., 2001. Çukurova koşullarında nohutta (Cicer arietinum L.) bazı önemli özellikler yönünden genotip $x$ çevre interaksiyonları ve uyum yeteneklerinin saptanması üzerine bir araştırma. Türkiye 4. Tarla Bitkileri Kongresi, 17-21 Eylül 2001, Tekirdağ

Mart D., 2006. Investigation of relations among ascochyta blight and plant morphology with multi-regrassion on winter planted chickpea (Cicer arietinum) varieties in the Çukurova Region. Ascochyta 2006, 2-6 Temmuz, Le Tronchet, France
Mart D., Çinkaya N., Karaköy T. and Keçeli A., 2010 Adaptation of registered chickpea (Cicer arietinum L.) varieties to çukurova region and investigation of quality values in regional conditions. Book Abstracts, $5^{\text {th }}$ International Food Legumes Research Conferance (IFLRCV) \& $7^{\text {th }}$ European Conferance on Grain Legumes (AEP VII); Legumes for Global Health Legume Crops and Products for Food, Feed and Environmental Benefits, April 26-30, 2010, Antalya

Muehlbauer F.J. and Singh K.B., 1987, Genetics of Chickpea. (M.C. Saxena, K.B. Singh) The Chickpea. CAB Int, Oxon UK., p. 99-125.

Phadnis B.A., Ekbote A.P. and Ainchwar S.S., 1970. Path-coefficient analysis in gram (C. arietinum). Bibloography of Chickpea Genetics and Breeding., 115: 915

Saxena M.C., 1980. Recent advences in chickpea agronomy. In: Proceedings of the First International Workshop on Chickpea Improvement, 28 Feb- 2 Mar 1979. ICRISAT, Hyderabat, India, s.89-96

Slim S.N. and Saxena M.C., 1993. Adaptation of spring-sown chickpea to the mediterranean basin. ii. factors influencing yield under drought. Field Crops Research, 34: 137-146.

Şehirali S., 1988. Yemeklik Tane Baklagiller. Ankara Üni. Ziraat Fak. Yay.: 1089, 435 s.

Şehirali S., 2002. Tohumluk ve Teknolojisi. Trakya Üni. Ziraat Fak., Tarla Bitkileri Böl., İstanbul 